\title{
Age-related dissociation of sensory and decision-based auditory motion processing
}

\author{
Alexandra A. Ludwig ${ }^{1,2 *}$, Rudolf Rübsamen ${ }^{1}$, Gerd J. Dörrscheidt ${ }^{4}$ and Sonja A. Kotz ${ }^{3 *}$ \\ ' Faculty of Biosciences, Pharmacy and Psychology, University of Leipzig, Leipzig, Germany \\ 2 Department of Otorhinolaryngology, Section of Phoniatrics and Audiology, University of Leipzig, Leipzig, Germany \\ ${ }^{3}$ Minerva Research Group "Neurocognition of Rhythm in Communication," Max Planck Institute for Human Cognitive and Brain Sciences, Leipzig, Germany \\ ${ }^{4}$ Mühle, Tiefurt, Weimar-Tiefurt, Germany
}

\section{Edited by:}

Hans-Jochen Heinze, University of

Magdeburg, Germany

Reviewed by:

Carles Escera, University of

Barcelona, Spain

Leighton B. Hinkley, University of

California, San Francisco, USA

\section{*Correspondence:}

Alexandra A. Ludwig, Department of Otorhinolaryngology, Section of

Phoniatrics and Audiology,

University of Leipzig, Liebigstrasse

10-14, D-04103 Leipzig, Germany.

e-mail: alexandra.ludwig@

medizin. uni-leipzig.de

Sonja A. Kotz, Minerva Research

Group "Neurocognition of Rhythm

in Communication," Max Planck

Institute for Human Cognitive and

Brain Sciences, Stephanstraße 1a,

04103 Leipzig, Germany.

e-mail: kotz@cbs.mpg.de
Studies on the maturation of auditory motion processing in children have yielded inconsistent reports. The present study combines subjective and objective measurements to investigate how the auditory perceptual abilities of children change during development and whether these changes are paralleled by changes in the event-related brain potential (ERP). We employed the mismatch negativity (MMN) to determine maturational changes in the discrimination of interaural time differences (ITDs) that generate lateralized moving auditory percepts. MMNs were elicited in children, teenagers, and adults, using a small and a large ITD at stimulus offset with respect to each subject's discrimination threshold. In adults and teenagers large deviants elicited prominent MMNs, whereas small deviants at the behavioral threshold elicited only a marginal or no MMN. In contrast, pronounced MMNs for both deviant sizes were found in children. Behaviorally, however, most of the children showed higher discrimination thresholds than teens and adults. Although automatic ITD detection is functional, active discrimination is still limited in children. The lack of MMN deviance dependency in children suggests that unlike in teenagers and adults, neural signatures of automatic auditory motion processing do not mirror discrimination abilities. The study critically accounts for advanced understanding of children's central auditory development.

Keywords: development, auditory motion processing, event-related brain potentials, MMN

\section{INTRODUCTION}

One of the fundamental capacities of the central auditory system is the extraction of spatial information, i.e., information about the position of a sound source in space. The physical variables that describe sound do not have a spatial dimension. Rather, they are used by the central processing system to establish the representation of auditory space. Specifically, the azimuthal position of auditory objects is coded by interaural time differences (ITDs), i.e., differences in sound arrival time at both ears and interaural intensity differences (IIDs), produced by the head shadow effect.

Interaural cues do not only play a role in the perception of stationary auditory signals but also in the processing of moving auditory objects, although the underlying mechanisms are still not fully understood. Animal studies have found motionsensitive auditory space maps in the midbrain (owl: Knudsen and Konishi, 1978; guinea pig: King and Palmer, 1983; cat: Rauschecker and Harris, 1989), and also neurons in the auditory cortex that are sensitive to moving auditory stimuli (monkey: Ahissar et al., 1992). Corresponding studies in humans yielded ambiguous results. Some studies support the hypothesis of contralateral dominance in auditory motion processing by showing stronger activation in the cortex contralateral to the direction of motion and attributing the processing to the planum temporale (Warren et al., 2002; Krumbholz et al., 2005, 2007). Other studies, however, suggest lateralized right-hemispheric processing.
Griffiths et al. (1998) found stronger activation to simulated moving sound sources in the right than in the left parietal cortex (Griffiths et al., 1998). Also, the primary auditory cortex on either side showed no differences in activation to moving compared to stationary sound sources (Griffiths et al., 1998; Smith et al., 2007) but an overall slightly stronger activation to both types of stimuli on the right side (Smith et al., 2007). Correspondingly, patients with unilateral cortex lesions can lose the ability to perceive motion when the right hemisphere is affected (Bisiach et al., 1984; Griffiths et al., 1996).

While many studies have focused on auditory spatial processing in adults, studies about the respective capabilities in children are sparse. Furthermore, most of these studies employ only stationary stimuli. The minimum audible angle (MAA) has been reported to be adult-like at the age of 5 years (Litovsky, 1997). Studying the development of auditory lateralization up to adulthood, Kaga (1992) found large improvements for the discrimination of ITD in 4-6-year-old children and only minimal improvements thereafter. Pertaining to motion processing in children, it has been shown that the ability to track a moving auditory object reaches adult levels not before 10-12 years of age (Cranford et al., 1993). In a previous behavioral experiment conducted in our laboratory, children aged six/seven were unable to discriminate simulated lateral moving sound sources based on binaural earphone stimulation with ITDs (unpublished data). It is not 
clear whether this inability emerges from delayed early signal processing in the developing central auditory system or rather from immature executive control associated with the discrimination process.

To address such potentially confounding factors, we investigated the processing of ITDs by recording event-related brain potentials (ERPs) using a mismatch negativity (MMN) paradigm. The MMN is an ERP component elicited when a regular sound sequence of homologous stimuli is interrupted by rare deviant stimuli that differ in one feature (Näätänen et al., 1978, 1982; Schröger, 1997). It has been proposed that MMN is evoked if the representation of the current deviant signal is not consistent with the memory trace of the preceding standard signals (Näätänen et al., 1978; Schröger, 1998). This approach allows the acquisition of cortical processes related to discrimination of acoustic features, either with or without the participant's attention on the stimuli (Schröger et al., 1992; Alain et al., 1994). Since these measurements can be done passively, limitations due to unknown cognitive influences should be minimized. Thus, MMN recordings are beneficial in the examination of auditory processing, as they overcome difficulties such as limited attention span (Alho et al., 1992; Paavilainen et al., 1993). In children, MMNs have been elicited by frequency deviants (Čeponiené et al., 1998; Gomes et al., 1999), duration deviants (Korpilahti and Lang, 1994; Joutsiniemi et al., 1998), and deviants in speech (Kraus et al., 1993a; Kurtzberg et al., 1995). The MMN in children is mostly comparable to that of adults (Gomes et al., 1999, 2000), but latencies are, depending on age, about $50 \mathrm{~ms}$ longer (Shafer et al., 2000; Maurer et al., 2003), and amplitudes larger (Kraus et al., 1992, 1993b).

Typically, the amplitude of the MMN decreases if the difference between the standard and the deviant is reduced (Scherg et al., 1989; Näätänen et al., 2001). In a study of children aged 8-12, the same decrease in MMN amplitudes with decreased differences between standard and deviants was observed (Gomes et al., 2000). This suggests that in children the MMN amplitude can be correlated with discrimination performance (Čeponiené et al., 1999; Kraus et al., 1999). This is in agreement with reports of a positive correlation between the reliability of correct decisions in behavioral experiments and the amplitudes of the MMN: while in children with good discrimination performance a noticeable MMN was elicited, this was not the case in those who performed badly (Kraus et al., 1996).

In the present study, MMNs were acquired from participants ranging from 6 to 20 years of age to investigate whether elevated behavioral discrimination thresholds for ITDs in children aged $6 / 7$ years are due to deficiencies evolving from the active discrimination process, or are an indication of immature sensory deviance detection reflecting limited processing capabilities.

We hypothesized that, in the case of an immature auditory system, a large (or easy to discriminate) deviant should elicit a clear MMN, whereas a hardly discernable deviant (considering the child's individual behavioral performance) should elicit no MMN. In contrast, if the observed elevated discrimination thresholds originate from immature executive functions (i.e., sensory auditory processing is fully developed) both deviants should elicit MMNs, but with magnitude-dependent amplitudes. All our measurements were based on each participant's individual discrimination threshold, and two different deviants were employed: (1) the just noticeable difference (threshold) and (2) a difference $20 \mathrm{~ms}$ above the subject's threshold. MMN amplitudes of $6 / 7$-year-old children were compared to those of $12 / 13$ year olds (teenagers) and adults.

\section{MATERIALS AND METHODS PARTICIPANTS}

The youngest children that could be reliably tested with the three-interval forced-choice test design (3IFC; cf. procedure) and performed above chance level were children aged $6 / 7$ years ("children") (mean: 6.5; SD: 0.5; 10 male, 10 female). Their performance was compared to that of a group of 12/13 year-old adolescents ("teens") (mean: 12.5; SD: 0.5; 10 male, 10 female), and to the performance of young adults aged 18-23 years ("adults") (mean: 20.6; SD: 2.2; 10 male, 10 female). The children were recruited from state elementary and secondary schools. Parents of all children gave informed written consent for participation in the study. All participants had audiometric thresholds of $20 \mathrm{~dB}$ HL (hearing level) or better, bilaterally, at octave frequencies from 250 to $8000 \mathrm{~Hz}$ (ANSI, 1996). They had no history of language impairment, peripheral or cochlear hearing disorders, or any neurological deficits. The study was approved by the Institutional Review Board of the Max-Planck-Institute for Human Cognitive and Brain Sciences.

\section{BEHAVIORAL TESTS \\ Stimuli}

All stimuli were generated using a real time processor (RP2.1, Tucker-Davis-Technologies, TDT, System III). Signals were amplified by a headphone driver (HB7) and presented through circumaural headphones (Beyerdynamic 770 Pro).

The stimuli consisted of $500 \mathrm{~Hz}$ tone bursts, which were binaurally presented. All stimuli had a duration of $250 \mathrm{~ms}$ including cosine-square ramps of $10 \mathrm{~ms}$. Reference signals generated a stationary percept localized centrally on the interaural axis and will be referred to als "noITD signal." Deviant stimuli had the same overall duration, but the signal in one channel (i.e., ear) ended earlier than in the respective other one (Bungert-Kahl et al., 2004). This ITD caused a lateralized auditory percept moving from a central position to the side of the longer stimulus (i.e., moving to the left or to the right side). This stimulus will be referred to as "ITD off signal."

At the beginning of the experiment, the hearing threshold for the noITD signal was estimated for both ears separately: beginning with $90 \mathrm{~dB}$ SPL (sound pressure level), the intensity of the stimulus was gradually decreased until the participant indicated that he or she could no longer hear the signal by pressing a button (first response). Next, starting with an attenuation of $120 \mathrm{~dB}$, the intensity of the stimulus was gradually increased until the participant indicated perception of the signal via button press (second response). The threshold was assumed as the mean of both responses. Based on these measurements, the intensity of the stimuli was set to $35 \mathrm{~dB}$ SL (sensation level). This level provided a comfortable volume and a constant sensation level across all participants. At the same time, it prevented any bone-conducted 
crosstalk between the ears, which could have obscured the results.

\section{Procedure}

Testing was conducted in a quiet room. The behavioral discrimination test was based on a three-interval forced-choice (3IFC) paradigm. Three signals were presented to the listener (interstimulus interval: $750 \mathrm{~ms}$ ), who had to discriminate one deviant signal from two identical reference signals by pressing the corresponding button on a response box.

The test started with three "familiarization" trials using large above-threshold interaural duration differences. By responding appropriately, participants indicated that they understood the test procedure. The initial duration difference between deviant and reference signals in the trials to follow was set to $140 \mathrm{~ms}$. During the course of the first eight trials the duration difference was decreased in steps of $10 \mathrm{~ms}$. Within the first eight trials, two incorrect responses in series stopped the first phase. If the first eight trials had passed without any wrong response, the first incorrect response ended the first phase. In the 10 trials of the second phase, an adaptive strategy was employed to get a closer evaluation of the near-threshold range. Participants' responses obtained so far were used to estimate the psychometric function (Gelfand, 1996) using a maximum-likelihood procedure (Pentland, 1980).

As a basic form of the psychometric function we applied a logistic function (1):

$$
p(t)=x_{4}+\left(x_{3}\right) /\left(1+e^{-\left(t-x_{1}\right) x_{2}}\right)
$$

where $p(t)$ is the probability of the correct response for a given $\Delta$ signal (duration difference), $x_{1}$ is the range of values included in the estimation of the logistic function, $x_{2}$ describes the shape of the logistic function $\left(x_{2}=4 \times \operatorname{slope}\left(x_{1}\right) / x_{3}\right), x_{3}$ described the range between minimum $\Delta$ signal and maximum $\Delta$ signal (assumed as 1.0) of the function and $x_{4}$ the minimum $\Delta$ signal at $1 / 3$. The duration difference as the test variable for the following trial was taken from the actual estimate of the psychometric function as the specific value which should lead to a hit response with a probability of approximately $0.4,0.5,0.8$, or 0.9 , the latter values taken in random order. At the end of this adaptive phase, the duration discrimination threshold was taken from the estimated psychometric function as the duration having a hit probability of $2 / 3$ (67\%), i.e., midway between guess probability and 100\% (cf. also Freigang et al., 2011).

Thresholds for lateralization to the left and to the right side were determined separately. Deviants used for the oddball paradigm in the subsequent EEG (electroencephalogram) experiment were chosen based on individual discrimination thresholds:

- small deviant, lateralization to the left side ("SL"): subject's discrimination threshold,

- small deviant, lateralization to the right side ("SR"): subject's discrimination threshold,

- large deviant, lateralization to the left side (" $L L "): 20 \mathrm{~ms}$ above subject's threshold,

- large deviant, lateralization to the right side (" $L R$ "): $20 \mathrm{~ms}$ above subject's threshold.
Each behavioral threshold estimation lasted approx. Two to three minutes (for lateralization to the left and to the rights, respectively) and was carried out at the beginning of the experimental session. The overall duration of the experiment (including preparation of the EEG measurements and data acquisition) was about $3 \mathrm{~h}$. Testing was performed in a single session in adults and in two separate one and a half hour sessions (including individual breaks) in children.

\section{EEG MEASUREMENT \\ Stimuli}

Stimuli for the EEG experiment were the same as in the behavioral testing; one signal with no interaural time difference (no ITD signal) and signals with different ITD at stimulus offset $\left(\right.$ ITD $_{\text {off }}$ signal). Tailored ITD stimuli were created for each subject according to individually estimated discrimination thresholds in the behavioral test. During EEG recordings, signals were presented binaurally through circumaural headphones (Beyerdynamic 770 Pro). For a description of the intensity adjustment, please see above ("Stimuli" in the Section "Behavioral Tests").

\section{Procedure}

The experiment was controlled by the software Presentation ${ }^{\circledR}$ (version 9.7). Participants sat in a chair and were instructed to relax and ignore the stimuli while they watched a silent film with subtitles.

MMNs were recorded using an Oddball paradigm: rare events were occasionally delivered in a repetitive auditory stimulus sequence of frequent events. The inter-stimulus-interval varied between 500 and $1200 \mathrm{~ms}$. Each experiment was divided into four blocks. In every block there were two kinds of stimuli: signals with no interaural time difference (no ITD) and signals with an individually estimated interaural time difference (ITD off signal: "SL," "SR," "LL," or "LR," respectively). Within each block, the individual $\mathrm{ITD}_{\text {off }}$ signal was first used as rare event (deviant) with a probability of $20 \%$ (150 stimuli) and the no ITD signal served as frequent stimulus (standard) (probability: 80\%, 600 stimuli). In the second part of the block, the ITD off signal occurred as standard $(80 \%, 150$ stimuli) and the no ITD signal as deviant $(20 \%$, 40 stimuli).

\section{Data acquisition}

The EEG was recorded from $21 \mathrm{Ag} / \mathrm{AgCl}$-electrodes (F7/8, F3/4, $\mathrm{Fz}, \mathrm{FC} 3 / 4, \mathrm{~T} 7 / 8, \mathrm{C} 3 / 4, \mathrm{Cz}, \mathrm{CP} 5 / 6, \mathrm{P} 7 / 8, \mathrm{P} 3 / 4, \mathrm{Pz}, \mathrm{O} 1 / 2)$ placed on the participants' scalps according to the international 10-20 system (Jasper, 1958). The ground electrode was placed on the sternum. Two additional electrodes A1 and A2 were placed at left and right mastoid positions, respectively. During recording, A1 served as reference, but data was re-referenced off-line to linked mastoids (Näätänen, 1995) to enhance the signal-to-noise ratio (Schröger, 1998). The signals were sampled at $250 \mathrm{~Hz}$. An anti-aliasing filter of $67.5 \mathrm{~Hz}$ was applied during recording. To record eye movements, two electrodes were placed above and below the right eye (vertical electrooculogram, EOG), and two were placed at the outer canthus of each eye (horizontal EOG). Impedances were kept below $5 \mathrm{kOhm}$ by the application of a saline gel. 
The recording of the EEG signal was subserved by PortiS/32-amplifiers (Twente Medical Systems) and the XREFA software (Max Planck Institute for Cognitive and Brain Sciences, Leipzig).

\section{DATA ANALYSIS}

The discrimination thresholds were analyzed using the software SigmaStat 3.0.1. Since the acquired values were not normally distributed, group differences were estimated using the MannWhitney rank sum test.

The EEG raw data were analyzed using the software EEProbe 3.2. (Max Planck Institute for Cognitive and Brain Sciences, Leipzig). First, data were corrected for ocular artifacts. Periods exceeding a maximum of $40 \mu \mathrm{V}$ were excluded from further analysis. An additional visual inspection of the data was done to reject other possible artifacts such as drifts and muscle artifacts. Table 1 shows the mean and standard error of averaged trials for each age group, deviant, and condition. A $2 \times 2$ repeated measures analysis of variance (within factors "deviant magnitude" and "direction of motion," between factors "age group") yielded no significant differences of accepted sweeps between age groups and conditions.

The exact time points of the occurrence of the ITD (deviant onset) were defined for every participant separately. The EEG was then divided into $600 \mathrm{~ms}$ stimulus-locked epochs covering the period from -100 to $500 \mathrm{~ms}$ relative to deviant onset. The artifact-free epochs for every stimulus were baseline-corrected to the $100 \mathrm{~ms}$ period prior to deviant onset. For every condition, single subject averages were computed for the $\mathrm{ITD}_{\text {off }}$ signal used as

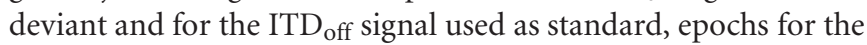
noITD signal were discarded. ERPs were then averaged for all participants in each age group (group mean averages). In a final step, MMN was quantified by subtracting the ERP evoked by the ITD off signal used as standard from the ERP evoked by the ITD off $_{\text {signal }}$ used as deviant.

A preliminary timeline analysis assessed differences between mean ERP amplitudes of the standard-ITD off $_{\text {signals and mean }}$

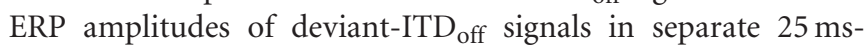
wide non-overlapping windows from 0 to the end of the epoch.

Table 1 | Percentage (Mean \pm SE) of averaged trials for each age group, deviant, and condition.

\begin{tabular}{lllll}
\hline Age group & Condition & Motion to: & Mean [\%] & SE [\%] \\
\hline \multirow{2}{*}{ Adults } & Large deviant & Left & 71.4 & 2.9 \\
& \multirow{2}{*}{ Small deviant } & Right & 70.3 & 3.0 \\
& & Left & 69.9 & 2.6 \\
\multirow{2}{*}{ Teens } & Large deviant & Left & 71.4 & 3.1 \\
& \multirow{3}{*}{ Small deviant } & Right & 63.8 & 4.0 \\
& & Left & 63.9 & 3.9 \\
& \multirow{3}{*}{ Children } & Right & 63.9 & 3.6 \\
& \multirow{2}{*}{ Large deviant } & Left & 63.8 & 4.2 \\
& Small deviant & Right & 62.6 & 2.9 \\
& & Left & 62.1 & 2.6 \\
& & Right & 60.3 & 3.2 \\
& & &
\end{tabular}

A sliding window was used to resolve possible latency differences between age groups. This analysis allowed defining a mean amplitude time window of 76 to $176 \mathrm{~ms}(p<0.0001)$ in all age groups that was used to quantify difference waves. The significance of the MMN response was assessed by comparing the mean MMN amplitude in this time window against zero using a one-group one-tailed $t$-test. Two regions of interest (ROI), each containing averaged data from eight electrodes, were defined: left (F3/7, FC3, T7, C3, CP5, and P3/7), and right (F4/8, FC4, T8, C4, CP6, and P4/8), covering the left and right hemisphere, respectively, from frontal to parietal areas. Repeated measures analysis of variance (ANOVA) for these ROIs incorporated the between-subject factor "group," and within-subject factors "magnitude" (small vs. large deviant), "direction" (simulated direction of motion: to the left vs. to the right), and "hemisphere" (left vs. right). Significant interactions were followed by analyses of variance with a reduced factorial design. Post-hoc analyses were done with $t$-tests, Bonferroni-corrected for multiple comparisons. Only post-hoc tests that were significant after Bonferronicorrection are reported. A Satterwhaite adjustment was applied when an inhomogeneity of variances was detected. Levels of significance for all tests were ${ }^{*} p<0.05 ;{ }^{* *} p<0.01$; ${ }^{* *} p<0.001$, respectively.

\section{RESULTS}

\section{DISCRIMINATION THRESHOLDS}

Just noticeable differences for $\mathrm{ITD}_{\text {off }}$ decreased with increasing age (Figure 1). The largest improvements in discrimination performance were found between children (mean: $62.9 \mathrm{~ms}$, SE: $9.9 \mathrm{~ms}$, range: $2.0-120.1 \mathrm{~ms}$ ) and teens (mean: $14.1 \mathrm{~ms}$, SE: $2.8 \mathrm{~ms}$, range: $2.3-49.9 \mathrm{~ms}$ ). A further reduction in discrimination thresholds was observed between teens and adults (mean: $8.8 \mathrm{~ms}$, SE: $1.1 \mathrm{~ms}$, range: $1.7-21.4 \mathrm{~ms}$ ). Group differences were highly significant between children and teens $(p=0.001)$ and between children and adults $(p<0.001)$. No significant differences were found between teens and adults.

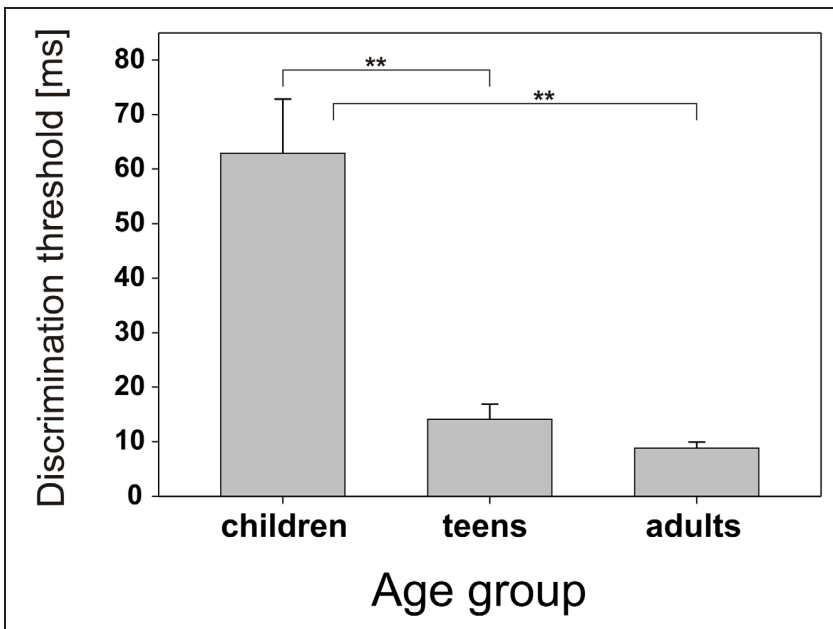

FIGURE 1 | Behavioral discrimination thresholds. Group means and standard error for interaural duration discrimination for children, teens, and adults. 


\section{LARGE DEVIANTS}

Figure 2 depicts the ERPs elicited by the $\mathrm{ITD}_{\text {off }}$ signal used as deviant and the $\mathrm{ITD}_{\text {off }}$ signal used as standard as well as the deviant-standard difference waves in A [children], B [teens], and C [adults], respectively, for the large deviant. Pure tone bursts differing in their duration convey the percept of dynamic auditory objects moving either to the left (solid lines) or to the right (dashed lines). In all age groups, these signals elicited prominent MMNs (see Methods for details). Mean amplitudes, standard deviations, and $t$-values are listed in Table 2. For all age groups, MMN amplitudes were significant in both conditions over both hemispheres.

\section{SMALL DEVIANTS}

Figure 3 shows the ERPs and difference waves elicited by the ITD off signal as deviant and the ITD $_{\text {off }}$ signal as standard in A [children], B [teens], and C [adults], respectively, for the small contrast. In adults, no significant MMNs were elicited by small

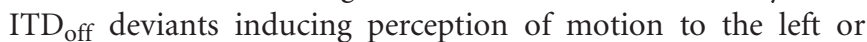
to the right (Figure 3C). The small negativities, encountered at electrodes F3 and F4 (motion to the right), did not reach statistical significance (Table 3). In teens, MMN reached significance only for perceived motion to the left over right hemisphere scalp locations (Figure 3B, solid lines). No MMN was evoked at all other electrodes. However, in 6/7-year-old children, clearly discernable and prominent MMNs were elicited by small deviants in both stimulus conditions, and reached significance over both hemispheres (Figure 3A, Table 3).

The 6/7-year-old children yielded conspicuous results. A subgroup of five girls and two boys (five six-year-olds and two seven-year-olds) showed discrimination thresholds comparable

Table 2 | MMN (large deviant) for adults, teens, and children: amplitudes und significance.

\begin{tabular}{|c|c|c|c|c|c|}
\hline Age group & Condition & Hemisphere & Mean $[\mu \mathrm{V}]$ & $\mathbf{S D}[\mu \mathbf{V}]$ & $t$-value \\
\hline \multirow[t]{4}{*}{ Adults } & \multirow[t]{2}{*}{ Motion left } & Left & -1.36 & 0.89 & $-6.86^{* * *}$ \\
\hline & & Right & -1.44 & 0.82 & $-7.88 * * *$ \\
\hline & \multirow[t]{2}{*}{ Motion right } & Left & -1.38 & 0.82 & $-7.53^{* * *}$ \\
\hline & & Right & -0.88 & 0.63 & $-6.21^{* * *}$ \\
\hline \multirow[t]{4}{*}{ Teens } & \multirow[t]{2}{*}{ Motion left } & Left & -1.56 & 1.20 & $-5.68^{* * *}$ \\
\hline & & Right & -1.59 & 1.36 & $-5.09^{* * *}$ \\
\hline & \multirow[t]{2}{*}{ Motion right } & Left & -1.47 & 1.51 & $-4.25^{* * *}$ \\
\hline & & Right & -1.15 & 1.72 & $-2.91^{* *}$ \\
\hline \multirow[t]{4}{*}{ Children } & \multirow[t]{2}{*}{ Motion left } & Left & -1.83 & 1.34 & $-6.40^{* * *}$ \\
\hline & & Right & -1.52 & 1.77 & $-4.03^{* * *}$ \\
\hline & \multirow[t]{2}{*}{ Motion right } & Left & -1.54 & 2.42 & $-2.98^{* *}$ \\
\hline & & Right & -1.00 & 2.36 & $-2.00^{*}$ \\
\hline
\end{tabular}

MMN amplitudes (Mean) und standard deviation (SD) in the time window: 76-176 ms for conditions "motion to the left" and "motion to the right" at the two hemispheres. t-test: ${ }^{*} p<0.05$; ${ }^{* *} p<0.01$; ${ }^{* * *} p<0.001$.
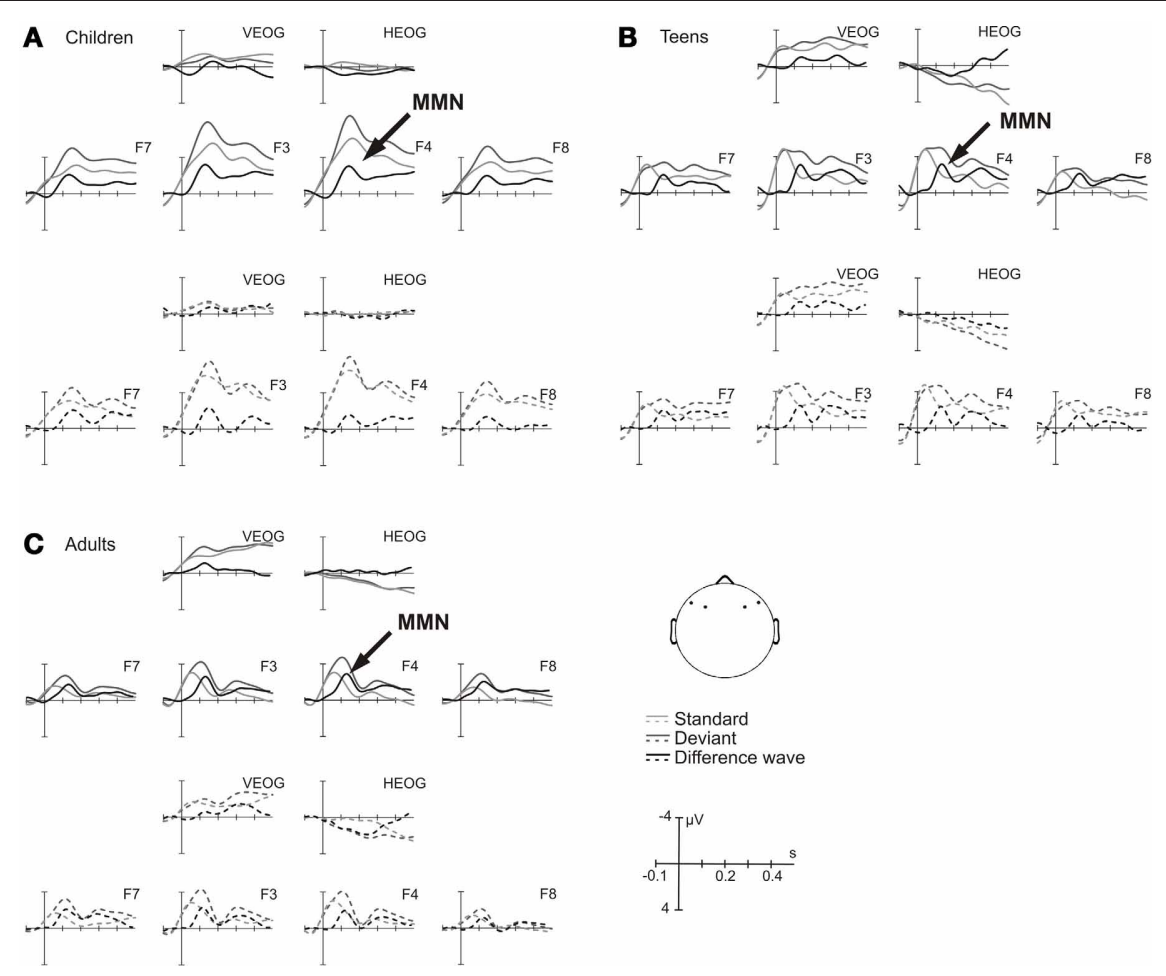

FIGURE 2 | Large deviant-ERPs and difference waves. Event-related potentials elicited by the ITD off signal used as deviant (dark gray line) and as standard (light gray line) as well as the respective difference waves (MMN, black line) in (A) children, (B) teens, and (C) adults, respectively. In each age

group, solid lines depict waves for a simulated motion to the left, dashed lines for a simulated motion to the right at selected electrodes: F7, F3, F4, and F8, respectively. Vertical and horizontal eye electrodes: VEOG and HEOG. Data were $7 \mathrm{~Hz}$ low pass filtered for visualization purposes. 


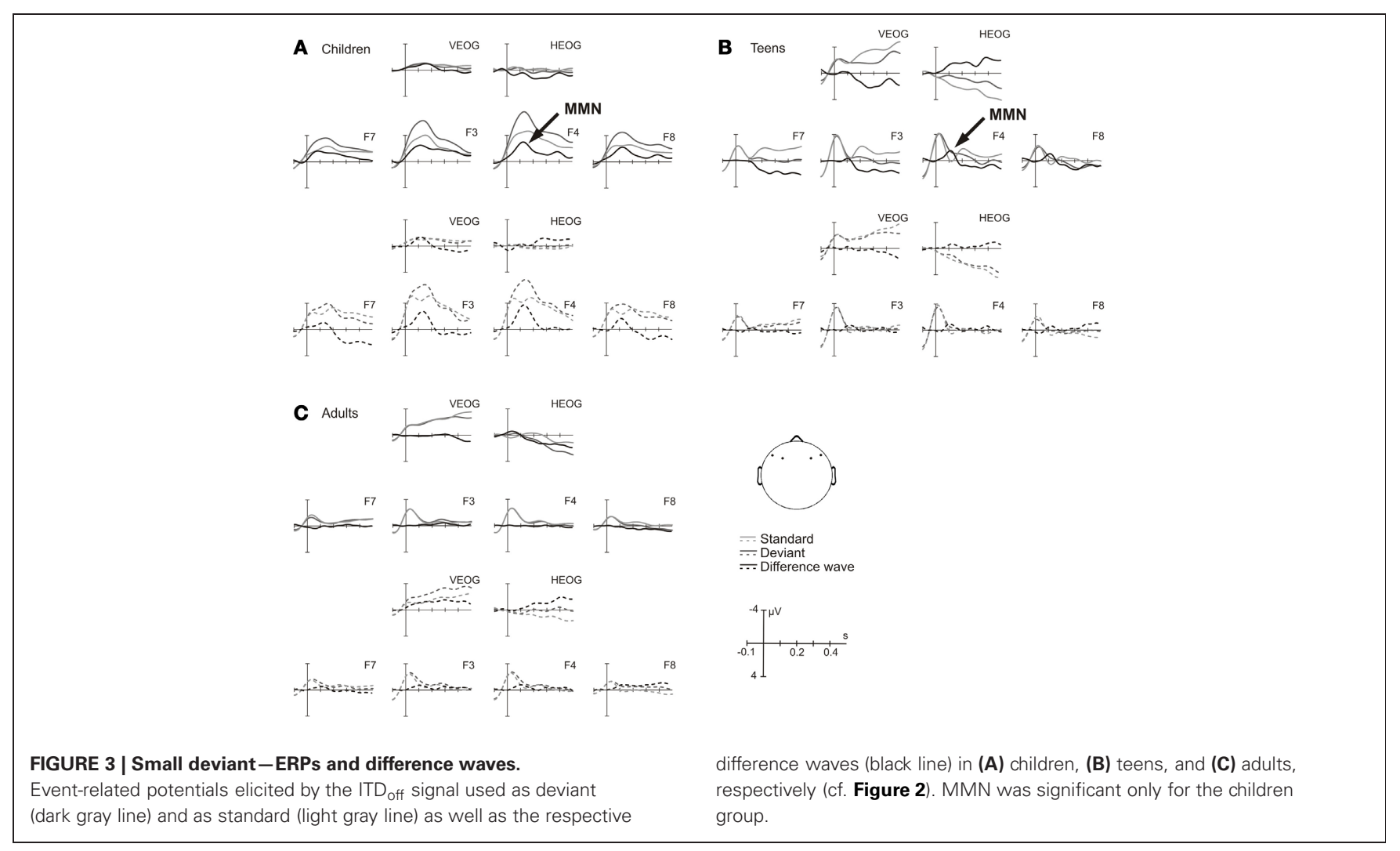

Table 3 | MMN (small deviant) for adults, teens, and children: amplitudes und significance.

\begin{tabular}{|c|c|c|c|c|c|}
\hline Age group & Condition & Hemisphere & Mean $[\mu \mathrm{V}]$ & $S D[\mu V]$ & $t$-value \\
\hline \multirow[t]{4}{*}{ Adults } & \multirow[t]{2}{*}{ Motion left } & Left & 0.097 & 0.86 & 0.50 \\
\hline & & Right & 0.067 & 0.98 & 0.35 \\
\hline & \multirow[t]{2}{*}{ Motion right } & Left & -0.30 & 1.08 & -1.23 \\
\hline & & Right & -0.35 & 1.09 & -1.43 \\
\hline \multirow[t]{4}{*}{ Teens } & \multirow[t]{2}{*}{ Motion left } & Left & -0.14 & 1.87 & -0.33 \\
\hline & & Right & -0.98 & 1.47 & $-2.90^{* *}$ \\
\hline & \multirow[t]{2}{*}{ Motion right } & Left & -0.07 & 1.50 & -0.19 \\
\hline & & Right & -0.17 & 1.291 & -0.57 \\
\hline \multirow[t]{4}{*}{ Children } & \multirow[t]{2}{*}{ Motion left } & Left & -1.59 & 2.06 & $-3.61^{* *}$ \\
\hline & & Right & -2.06 & 2.46 & $-3.92^{* * *}$ \\
\hline & \multirow[t]{2}{*}{ Motion right } & Left & -1.81 & 2.09 & $-4.05^{* * *}$ \\
\hline & & Right & -1.87 & 1.59 & $-5.52^{* * *}$ \\
\hline
\end{tabular}

MMN amplitudes (Mean) und standard deviation (SD) in the time window: 76-176 ms for conditions "motion to the left" and "motion to the right" at the two hemispheres. $t$-test: ${ }^{* *} p<0.01 ; * * * 0.001$.

to those of teens and adults, i. e. thresholds below or equal to 15 ms (mean: 7.7, SE: 1.7). Interestingly, the MMN amplitudes of these "good performers" revealed pronounced MMNs for large as well as for small deviants (Figure 4).

\section{STATISTICAL ANALYSIS OF THE MMN}

Based on the results of the preliminary timeline analysis, statistical analysis was conducted on the mean amplitude of the

difference waves in the time window from 76 to $176 \mathrm{~ms}$ post deviant onset. Analysis of variance for repeated measures revealed main effects of group $\left(F_{(2,58)}=12.13, p<0.0001\right)$ and magnitude $\left(F_{(1,58)}=14.43, p=0.0004\right)$ as well as a significant interaction of group by magnitude $\left(F_{(2,58)}=9.19, p=0.0003\right)$. Post-hoc analysis ( $t$-test) showed no differences between groups for large deviants $(F<1)$. However, for small deviants, we found highly significant amplitude differences between children and teens $\left(t_{(39)}=-5.23, p<0.0001\right)$ and between children and adults $\left(t_{(40)}=6.58, p<0.0001\right)$, but not between teens and adults $\left(t_{(37)}=0.82, p=0.4151\right)$. This effect originated from the fact that small deviants failed to elicit mismatch negativities in teens and adults. Differences in MMN amplitudes between deviants were, therefore, highly significant for teens $\left(t_{(18)}=\right.$ $-3.67, p=0.0018)$ and adults $\left(t_{(19)}=-4.92, p<0.0001\right)$, but not for children.

Another factor tested was the direction of motion, which exerted a significant influence on MMN characteristics over the two hemispheres (direction by hemisphere interaction: $F_{(1,58)}=$ 6.11, $p=0.0164$ ) (Figure 5). Motion to the left resulted in larger amplitudes over the right (mean: $-1.27 \mu \mathrm{V})$ than over the left (mean: $-1.09 \mu \mathrm{V}$ ) hemisphere, whereas motion to the right caused larger amplitudes over the left (mean: $-1.12 \mu \mathrm{V}$ ) compared to the right (mean: $-0.93 \mu \mathrm{V}$ ) hemisphere.

In addition, an interaction of magnitude and hemisphere was found $\left(F_{(1,58)}=9.38, p=0.0033\right)$, resulting from the fact that the large deviant elicited larger left-hemispheric amplitudes and the small deviant elicited larger right-hemispheric amplitudes (Figure 6). The right-hemispheric larger MMNs for the small 


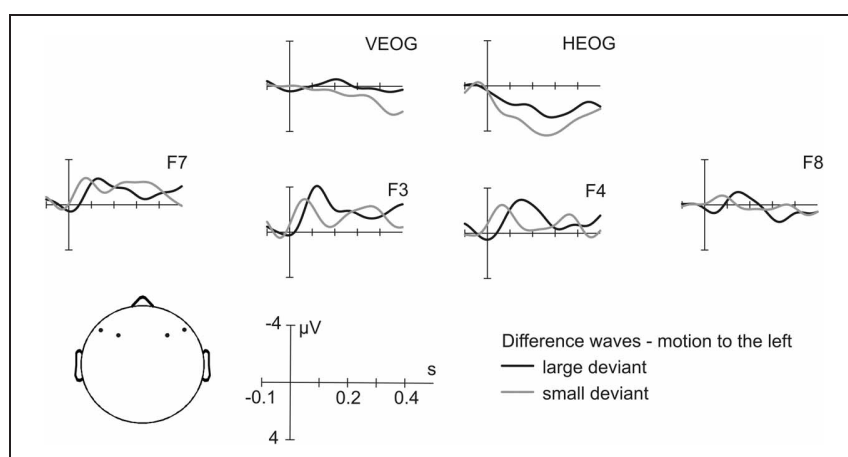

FIGURE 4 | MMN in children with adult-like behavioral discrimination performance. Simulated motion to the left, difference waves of ERP (Deviant-Standard) for the large deviant (black line) and the small deviant (gray line) at selected electrodes: F7, F3, F4, and F8. Vertical and horizontal eye electrodes: VEOG and HEOG.

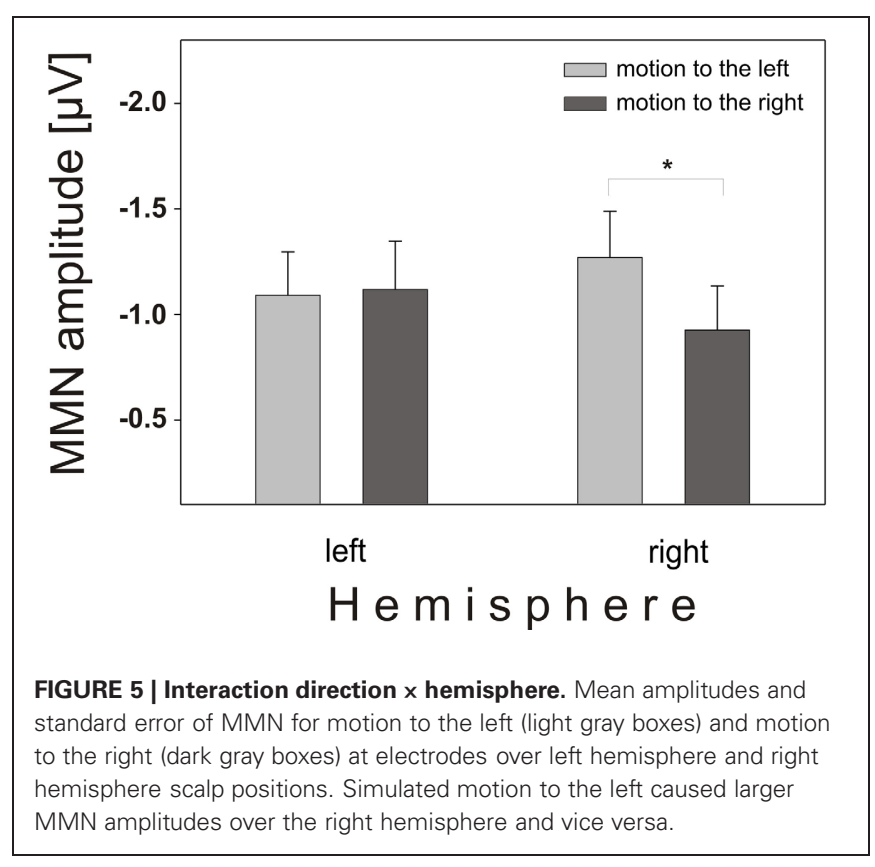

deviant condition are also evident in Figure 3, notably for teens (B) and children (A). Post-hoc t-tests revealed significant amplitude differences between deviants over the left hemisphere $\left(t_{(60)}=-4.38, p<0.0001\right)$.

\section{DISCUSSION}

The present experiment investigated the processing of simulated moving auditory objects, in children, teens, and adults. The study evaluated whether elevated thresholds in the behavioral discrimination test seen in 6/7-year-old children could be accounted for by restricted cognitive capabilities or instead mirror immature processing of the central auditory system. We employed the MMN to directly compare behavioral discrimination performance to electrophysiological correlates. Depending on each participant's individual discrimination threshold, two different deviants were chosen: (1) ITD off at threshold ("small deviant") and (2) ITD off $20 \mathrm{~ms}$ above threshold ("large deviant").

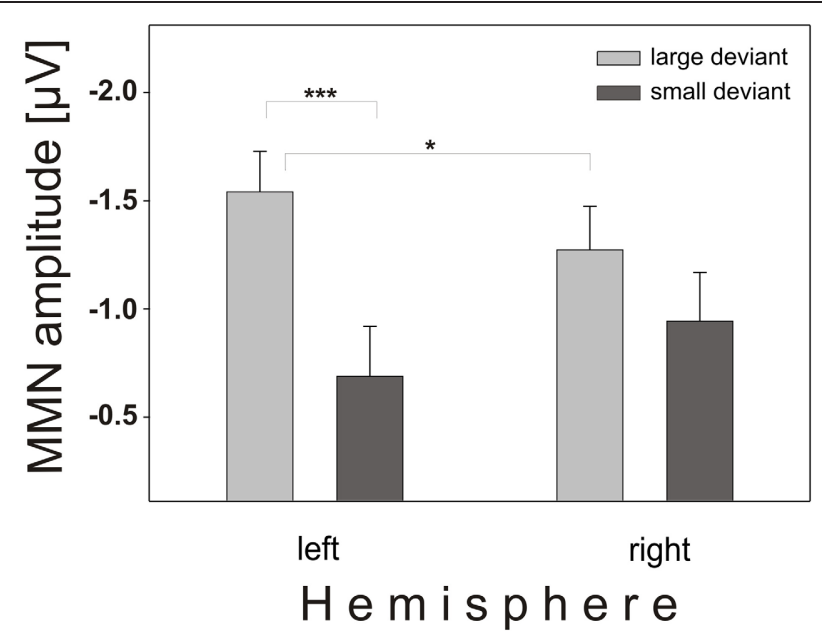

FIGURE 6 | Interaction magnitude $\mathbf{x}$ hemisphere. Mean amplitudes and standard error of MMN elicited by large (light gray boxes) and small (dark gray boxes) deviants over left and right scalp positions. While the large deviant caused larger amplitudes over the left hemisphere, the small deviant elicited larger amplitudes over the right hemisphere.

For large deviants, all age groups-children, teens, and adults - showed pronounced MMNs at frontal electrode-sites, without any prominent differences between age groups. Small deviants, however (1) failed to elicit an MMN in adults entirely, (2) lead to marginal MMN over right hemisphere electrodesites in teens, and, in contrast, (3) elicited prominent MMNs in children at all frontal electrode-sites.

The present results are in agreement with two other studies showing (1) that 6/7-year-old children are less capable of perceiving simulated auditory motion (Cranford et al., 1993), and (2) generally larger amplitudes of ERPs elicited by moving stimuli in young children (Jerger and Estes, 2002) compared to adolescents and young adults. However, relating to MMN elicitation, our findings challenge the simple predictions derived from previous findings. The children's apparent MMN in response to small deviants is not in agreement with our first hypothesis, which states that a hardly discernable deviant should elicit no MMN. The lack of magnitude-dependent amplitude increase, on the other hand, argues against the second assumption of an MMN dependency on deviance magnitude. It seems that the behavioral and MMN data in children do not show the same correspondence as seen in teens and in adults.

It could be argued that the behaviorally measured thresholds may not mirror the real just noticeable $\mathrm{ITD}_{\text {off }}$ differences, i.e., the high discrimination thresholds could have resulted from a lack of cognitive control rather than from impaired processing abilities. However, the correct responses of the children in the familiarization trials at the beginning of the test session showed that they understood the task and were able to perform adequately. Furthermore, each single test run took only about $3 \mathrm{~min}$ and should not have overstrained the children's attention. With respect to the understanding of task instructions, it is of special interest that the three-interval forced-choice procedure is a well-established paradigm and also appropriate for testing 
children (Elfenbein et al., 1993; Ari-Even Roth et al., 2002; Boets et al., 2006; Banai, 2008; Halliday et al., 2008; Moore et al., 2011). Also, in an analysis of frequency discrimination thresholds in relation to the age of the participants, Halliday et al. (2008) found the participants' IQ to be a covariate with a significant influence on the threshold. However, this influence did not vary with age. Although in our study, we did not measure indices of intelligence, it is not likely that our children participants had lower relative IQ scores than teenagers or adults. Thus, it is reasonable to assume that the rather high behavioral ITD $_{\text {off }}$ thresholds in children reliably indicate the respective performance.

Furthermore, in other studies, there were also some children with disproportionately high thresholds (Thompson et al., 1999; Halliday et al., 2008; Moore et al., 2011), but they had been excluded from further analysis, which is not the case in the current study, as we consider high variability in children's data (good, i.e., adult-like performers vs. bad performers) as part of normal development. It has been suggested that cognitive functions other than sensation and attention affect the development of auditory discrimination. This may include a greater influence of frontal and parietal cortical input on central auditory processing (Banai, 2008; Moore et al., 2011). One possible candidate for mediating integration of behaviorally relevant information, maintaining task-relevant information, and response execution is the prefrontal cortex (Miller and Cohen, 2001; Anderson et al., 2005). Along with prefrontal cortex maturation (Hwang et al., 2010), these functions presumably continue to develop into late childhood.

Another possible explanation could be that the children's MMN at threshold is a marker of implicit knowledge. It has been shown that violations of abstract regularities in sound sequences generate MMNs, whereas the participants were hardly able to actively discriminate the violations (van Zuijen et al., 2006; Paavilainen et al., 2007). It may be that the current MMN in response to a simulated moving auditory object in children reflects pre-attentive processing ("sensory intelligence"), rather than post-perceptual-cognitive operations (Näätänen et al., 2010) as it would be the case in an active discrimination task.

The presence of the MMN for small deviants indicates that the automatic ITD off processing in children is already functional and most likely the automatic change detection system is capable

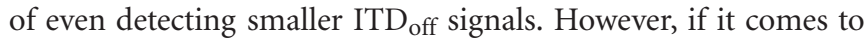
active discrimination, the children did not perceive the signals differing in $\mathrm{ITD}_{\text {off }}$ as different auditory objects. Thus, it is possible that in young children behavioral discrimination places greater demands on auditory processing than does automatic detection of ITD $_{\text {off }}$ signals. Possibly, children may differ in their ability to effectively utilize subtle sensory cues for composing binaurally fused moving auditory objects. Thus, passive automatic ITD off $_{\text {f }}$ detection and active behavioral discrimination in children seem to be less closely correlated than in adolescents and adults.

We cannot completely rule out the possibility that the behavioral discrimination thresholds have been underestimated in these children, but it was the best performance the children could achieve with the 3IFC paradigm. Future studies employing systematically decreasing contrasts should show which ITD off $_{\text {f }}$ represents the threshold for generating MMN in children.

\section{INVARIANT MMN AMPLITUDE}

In the present experiment, specific care was taken to directly relate ERP measurements to the individual thresholds of ITD $_{\text {off dis- }}$ crimination in each child. Referring to the assumption that MMN amplitudes decrease with decreasing stimulus difference (ITD: Nager et al., 2003, spatial location: Sonnadara et al., 2006), small deviants should have yielded smaller MMNs than large deviants. However, this was not the case. The results show that children, in contrast to adults and teens, do not exhibit a gradual MMN as a function of stimulus difference, since MMNs elicited by large deviants were not larger in amplitude than MMNs to small deviants, as expected assuming the previously reported deviance dependency. In this respect it is of note that there are no analogous ITD $_{\text {off }}$ studies in children, but there are indeed several other studies showing no systematic changes in MMN amplitudes with increasing stimulus difference (cf. Paavilainen et al., 1989; van der Stelt et al., 1997; Colin et al., 2002). Recently, it has been argued that the frequently detected relation between MMN amplitude and the amount of stimulus deviance is almost completely caused by amplitude changes of the N1 (Horváth et al., 2008; May and Tiitinen, 2010). Every acoustic signal evokes an N1 (Näätänen and Picton, 1987), the amplitude of which increases with increasing acoustic difference between stimuli (Butler, 1968; Näätänen et al., 1988). Horváth et al. (2008) used a design that excluded the N1 effect by employing acoustically identical stimuli and found no correlation between MMN amplitude and stimulus difference. In the present study we similarly compared acoustically identical stimuli. Moreover, there was also no overlay of MMN with the N1 component, because deviant onset occurred after stimulus onset. Thus, our N1-independent design renders the actual lack of MMN amplitude differences less surprising. Interestingly, a subgroup of children showed discrimination thresholds comparable to those of adults and in these children the MMN amplitudes also did not co-vary with the size of deviants. Hence, even these children classified as "good performers" have pronounced MMN responses to deviants at their individual thresholds while adults and teens do not. Presumably, in these children the apparent MMN at threshold reflects some kind of increased processing effort, possibly caused by a larger amount of simultaneously active neurons and/or lesser synchronization of these neurons.

\section{MMN IN TEENAGERS AND ADULTS}

The current experiment supports some kind of magnitudedependent amplitude increase (Sams et al., 1985; Scherg et al.,

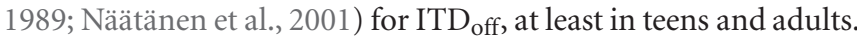
In adults, deviants with ITDs at stimulus offset $20 \mathrm{~ms}$ above the individual discrimination threshold elicited prominent MMNs, whereas deviants at the behavioral threshold (detection probability of $67 \%$ on the psychometric function) did not. Such failures in MMN generation may be due to the fact that the subjects' attention was not required during ERP acquisition, while for the evaluation of the behavioral thresholds attention is indispensable (Schröger, 1997). During ERP acquisition, the engagement in a different task (i.e., watching a film and reading the subtitles) may have caused a threshold elevation. Such attentional shifts toward irrelevant deviant signals were repeatedly shown if the experimental task was only slightly demanding (Näätänen et al., 1982; 
Fitzgerald and Picton, 1983; Sams et al., 1985), but did not occur if the task was challenging (Alho et al., 1994). Ignoring stimuli, therefore, could have caused a threshold elevation.

In teens, small deviants showed a tendency to elicit an MMN that reached significance only at right-hemisphere electrodesites. This finding is in accord with two other studies that also showed decreased MMN amplitudes at near-threshold differences (Näätänen and Alho, 1997; Amenedo and Escera, 2000).

\section{MOTION}

The present bilateral stimulus presentation simulated moving signals from azimuthal midline to either side. Motion to the left resulted in larger MMN amplitudes over the right hemisphere and motion to the right in larger amplitudes over the left hemisphere. This contralateral processing of motion is consistent with other studies. Magnetoencephalogram (MEG) data suggested activation in the superior temporal cortex to be larger for motion in the contralateral hemifield (Xiang et al., 2002). Krumbholz and colleagues measured ERPs and identified larger negativities contralateral to the direction of motion presumably in supratemporal areas close to the auditory cortices (Krumbholz et al., 2007). In an fMRI experiment, the same authors also showed activation in the planum temporale for ITD-mediated motion processing (Krumbholz et al., 2005). So, the MMN amplitude patterns reported in the present study is in favor of a contralateral dominant processing of motion. However, it should be noted that two other studies found no MMN differences between hemispheres, neither for motion to the left nor to the right (Altman et al., 2005; Shestopalova and Vaitulevich, 2005). Still, most studies focusing on respective topics, postulate a right-hemispheric dominance for the processing of motion. When motion was simulated by interaural phase differences only the planum temporale of the right hemisphere was activated (Baumgart et al., 1999). Activation in the right posterior parietal cortex in addition to bilateral temporal cortex activation has been reported (Griffiths et al., 1998; Ducommun et al., 2002) independent of the direction of motion (Ducommun et al., 2002; Xiang et al., 2002). Patients with acquired brain lesions were no longer capable of perceiving motion if the respective area was affected (Griffiths et al., 1996). Comparing the processing of moving and stationary stimuli there was no enhanced fMRI activation for motion in the planum temporale, but generally a larger right-hemispheric activation for processing of spatial information (Smith et al., 2007). The hypothesis of basic asymmetries of interhemispheric processes in spatial processing is additionally confirmed by lateralization deficits in callosotomy patients (Hausmann et al., 2005).

Currently, there are two opposing hypotheses for the processing of motion. On the one hand, a right-hemispheric dominance is proposed, comprising predominantly areas in the parietal cortex. On the other hand, possible contralateral processing is considered, with an involvement of secondary and tertiary auditory cortex areas. Also conceivable would be a biphasic processing: first a contralateral processing in the auditory cortex followed by a more extended analysis in the right hemisphere. Still, the results of the present study support the notion of contralateral processing. In order to specify this contralaterality, source analyses in a subsequent experiment would be necessary.
It also has to be taken into account that unlike in other studies, the ITDs occurred at the end of the respective signals. This might have influenced the results, since onset and offset of acoustic stimuli are processed differently (Pratt et al., 2005, 2008). The above-mentioned motion studies used ITDs in a microsecondrange that, which - when occurring at the stimulus offset-were neither sufficient to be detected, nor do they generate the percept of auditory motion. For detection adults need $\mathrm{ITD}_{\mathrm{off}}$ of approximately 5-10 ms (Figure 1). The question is whether the respective signals are processed as binaurally fused percepts or whether left and right stimulus offsets are processed separately. It has been shown that the auditory system is capable of integrating stimulus changes within time windows of $200 \mathrm{~ms}$ as joint events (Sussman et al., 1999). Only a single MMN was elicited if consecutive stimulus changes occurred within a $200 \mathrm{~ms}$ interval, whereas two MMNs occurred for the respective changes in longer intervals (Sussman et al., 1999; Wang et al., 2005). Considering such an integration window, the ITD at the stimulus offset was integrated and processed as a single event. It is commonly accepted that ITD processing occurs at the level of the auditory brainstem (Siveke et al., 2007) and that auditory motion is pre-processed at various levels of the hierarchically organized afferent auditory system (Knudsen and Konishi, 1978; King and Palmer, 1983; Rauschecker and Harris, 1989; Ahissar et al., 1992). Such processing necessitates highest temporal precision (Louage et al., 2005), which presumably cannot be provided for by auditory cortex neurons (Lu et al., 2001; Eggermont, 2002). This implies that basic ITD processing has to be completed when neuronal information arrives at the auditory cortex. Patient studies support this hypothesis: using the same stimuli, patients with unilateral telencephalic lesions had unimpaired discrimination performance (BungertKahl et al., 2004; Biedermann et al., 2007). In addition, Winkler and colleagues propose that MMN is elicited by sensed differences rather than by mere physical features of standard and deviant (Winkler et al., 1995, 1998), and the present stimuli generate a prominent motion percept. Thus, it can be assumed that the fused ITD and consequently a simulated motion rather than separate offsets of the left and right signal parts have elicited the present MMNs.

\section{MMN-DETECTION OF INCONSISTENCIES}

Several studies have shown evidence that MMN represents a form of automatic detector indicating inconsistencies of an auditory continuum. However, it has been argued that MMN is solely elicited by an activation of "new" neurons (e.g., for frequency deviants due to tonotopic organization of auditory cortex) and that these neurons produce a larger N1 because they are not yet refractory (May and Tiitinen, 2010). The elicited MMN in the present experiment is a definite response to changes in the stimulus sequence. If stimuli with ITD $_{\text {off }}$ had been compared to

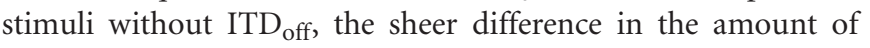
signal energy could have caused the negativities as well as the different negativities for different conditions. However, MMN has been evoked by acoustically identical signals as used as standard and deviant, and only the probability of occurrence (frequent or rare) had an influence on the evoked potentials (Eulitz and Lahiri, 2004). Furthermore, as stated above, in our design there is no 
overlay of $\mathrm{N} 1$ with $\mathrm{MMN}$ because deviant onset is at least about $150 \mathrm{~ms}$ after stimulus onset. Hence, we were able to eliminate the possibility that additional or completely other neuronal populations responded to the deviants. Thus, the present $M M N$ is a genuine marker of a violation in an auditory stimulus sequence.

\section{CONCLUSION}

The results of the present study show that active behavioral discrimination of moving lateralized auditory signals at the age of six/seven is worse than in teens and adults. Importantly, however, younger children invariably show large MMN amplitudes to large and to small ITD $_{\text {off }}$ deviants, whereas teens' and adults' MMNs

\section{REFERENCES}

ANSI (1996). Specifications for audiometers. [ANSI S3.6-1996]. New York: American National Standards Institute.

Ahissar, M., Ahissar, E., Bergman, H., and Vaadia, E. (1992). Encoding of sound-source location and movement: activity of single neurons and interactions between adjacent neurons in the monkey auditory cortex. J. Neurophysiol. 67, 203-215.

Alain, C., Woods, D. L., and Ogawa, K. H. (1994). Brain indices of automatic pattern processing. Neuroreport 6, 140-144.

Alho, K., Woods, D. L., Algazi, A., and Näätänen, R. (1992). Intermodal selective attention. II. Effects of attentional load on processing of auditory and visual stimuli in central space. Electroencephalogr. Clin. Neurophysiol. 82, 356-368.

Alho, K., Woods, D. L., and Algazi, A. (1994). Processing of auditory stimuli during auditory and visual attention as revealed by eventrelated potentials. Psychophysiology 31, 469-479.

Altman, J. A., Vaitulevich, S. P., Shestopalova, L. B., and Varfolomeev, A. L. (2005). Mismatch negativity evoked by stationary and moving auditory images of different azimuthal positions. Neurosci. Lett. 384, 330-335.

Amenedo, E., and Escera, C. (2000). The accuracy of sound duration representation in the human brain determines the accuracy of behavioural perception. Eur. J. Neurosci. 12, 2570-2574.

Anderson, V., Jacobs, R., and Harvey, A. S. (2005). Prefrontal lesions and attentional skills in childhood. J. Int. Neuropsychol. Soc. 11, 817-831.

Ari-Even Roth, D., Kishon-Rabin, L., and Hildesheimer, M. (2002). Auditory backward masking in normal hearing children. J. Basic Clin. Physiol. Pharmacol. 13, 105-115.

Banai, K. (2008). Auditory frequency discrimination development depends on the assessment procedure. J. Basic Clin. Physiol. Pharmacol. 19, 209-222.

Baumgart, F., Gaschler-Markefski, B. Woldorff, M. G., Heinze, H. J., and Scheich, H. (1999). A movementsensitive area in auditory cortex. Nature 400, 724-726.

Biedermann, F., Bungert, P., Dörrscheidt, G. J., Von Cramon, D. Y., and Rübsamen, R. (2007). Central auditory impairment in unilateral diencephalic and telencephalic lesions. Audiol. Neurootol. $13,123-144$.

Bisiach, E., Cornacchia, L., Sterzi, R., and Vallar, G. (1984). Disorders of perceived auditory lateralization after lesions of the right hemisphere. Brain 107 (Pt 1), 37-52.

Boets, B., Wouters, J., Van Wieringen, A., and Ghesquiere, P. (2006). Auditory temporal information processing in preschool children at family risk for dyslexia: relations with phonological abilities and developing literacy skills. Brain Lang. 97, 64-79.

Bungert-Kahl, P., Biedermann, F., Dörrscheidt, G. J., Von Cramon, D. Y., and Rübsamen, R. (2004). Psychoacoustic test tools for the detection of deficits in central auditory processing: normative data. Z Audiol. 43, 48-71.

Butler, R. A. (1968). Effect of changes in stimulus frequency and intensity on habituation of the human vertex potential. J. Acoust. Soc. Am. 44, 945-950.

Čeponiené, R., Cheour, M., and Näätänen, R. (1998). Interstimulus interval and auditory eventrelated potentials in children: evidence for multiple generators. Electroencephalogr. Clin. Neurophysiol. 108, 345-354.

Čeponiené, R., Service, E., Kurjenluoma, S., Cheour, M., and Näätänen, R. (1999). Children's performance on pseudoword repetition depends on auditory trace quality: evidence from

proved to be proportional to the magnitude of the deviance. The current study suggests that although the children's central auditory system is capable of automatic ITD $_{\text {off }}$ change detection, active discrimination is far behind the performance of older participants.

\section{ACKNOWLEDGMENTS}

The authors thank Sven Gutekunst, Anna Hasting, and Jonas Obleser for supporting experimental preparation and data analysis. Ulrike Barth helped with the recruitment of participants. We thank Rosie Wallis for helpful input on previous versions of the manuscript.

event-related potentials. Dev. Psychol. 35, 709-720.

Colin, C., Radeau, M., Soquet, A., Dachy, B., and Deltenre, P. (2002). Electrophysiology of spatial scene analysis: the mismatch negativity (MMN) is sensitive to the ventriloquism illusion. Clin. Neurophysiol. $113,507-518$

Cranford, J. L., Morgan, M., Scudder, R., and Moore, C. (1993). Tracking of "moving" fused auditory images by children. J. Speech Hear. Res. 36, 424-430.

Ducommun, C. Y., Murray, M. M., Thut, G., Bellmann, A., ViaudDelmon, I., Clarke, S., and Michel, C. M. (2002). Segregated processing of auditory motion and auditory location: an ERP mapping study. Neuroimage 16, 76-88.

Eggermont, J. J. (2002). Temporal modulation transfer functions in cat primary auditory cortex: separating stimulus effects from neural mechanisms. J. Neurophysiol. 87, 305-321.

Elfenbein, J. L., Small, A. M., and Davis, J. M. (1993). Developmental patterns of duration discrimination. J. Speech Hear. Res. 36, 842-849.

Eulitz, C., and Lahiri, A. (2004). Neurobiological evidence for abstract phonological representations in the mental lexicon during speech recognition. J. Cogn. Neurosci. 16, 577-583.

Fitzgerald, P. G., and Picton, T. W. (1983). Event-related potentials recorded during the discrimination of improbable stimuli. Biol. Psychol. 17, 241-276.

Freigang, C., Schmidt, L., Wagner, J., Eckardt, R., Steinhagen-Thiessen, E., Ernst, A., and Rübsamen, R. (2011). Evaluation of central auditory discrimination abilities in older adults. Front. Aging Neurosci. 3:6. doi: 10.3389/fnagi.2011.00006

Gelfand, S. A. (1996). Essentials of Audiology. New York, Stuttgart: Thieme Verlag.

Gomes, H., Molholm, S., Ritter, W., Kurtzberg, D., Cowan, N. and Vaughan, H. G. Jr. (2000). Mismatch negativity in children and adults, and effects of an attended task. Psychophysiology 37, 807-816.

Gomes, H., Sussman, E., Ritter, W., Kurtzberg, D., Cowan, N. and Vaughan, H. G. Jr. (1999), Electrophysiological evidence of developmental changes in the duration of auditory sensory memory. Dev. Psychol. 35, 294-302.

Griffiths, T. D., Rees, A., Witton, C. Shakir, R. A., Henning, G. B., and Green, G. G. (1996). Evidence for a sound movement area in the human cerebral cortex. Nature 383, 425-427.

Griffiths, T. D., Rees, G., Rees, A., Green, G. G., Witton, C., Rowe, D., Buchel, C., Turner, R., and Frackowiak, R. S. (1998). Right parietal cortex is involved in the perception of sound movement in humans. Nat. Neurosci. 1, 74-79.

Halliday, L. F., Taylor, J. L., Edmondson-Jones, A. M., and Moore, D. R. (2008). Frequency discrimination learning in children. J. Acoust. Soc. Am. 123, 4393-4402.

Hausmann, M., Corballis, M. C., Fabri, M., Paggi, A., and Lewald, J. (2005). Sound lateralization in subjects with callosotomy, callosal agenesis, or hemispherectomy. Brain Res. Cogn. Brain Res. 25, 537-546.

Horváth, J., Czigler, I., Jacobsen, T., Maess, B., Schröger, E., and Winkler, I. (2008). MMN or no MMN: no magnitude of deviance effect on the MMN amplitude. Psychophysiology 45, 60-69.

Hwang, K., Velanova, K., and Luna, B. (2010). Strengthening of topdown frontal cognitive control networks underlying the development of inhibitory control: a functional magnetic resonance imaging effective connectivity study. J. Neurosci. 30, 15535-15545.

Jasper, H. H. (1958). Report of the committee on the methods of clinical examination in 
electroencephalography. Electroencephalogr. Clin. Neurophysiol. 10, 370-375.

Jerger, J., and Estes, R. (2002). Asymmetry in event-related potentials to simulated auditory motion in children, young adults, and seniors. J. Am. Acad. Audiol. 13, 1-13.

Joutsiniemi, S. L., Ilvonen, T., Sinkkonen, J., Huotilainen, M., Tervaniemi, M., Lehtokoski, A., Rinne, T., and Näätänen, $\mathrm{R}$. (1998). The mismatch negativity for duration decrement of auditory stimuli in healthy subjects. Electroencephalogr. Clin. Neurophysiol. 108, 154-159.

Kaga, M. (1992). Development of sound localization. Acta. Paediatr. Jpn. 34, 134-138.

King, A. J., and Palmer, A. R. (1983). Cells responsive to free-field auditory stimuli in guinea-pig superior colliculus: distribution and response properties. J. Physiol. 342, 361-381.

Knudsen, E. I., and Konishi, M. (1978). A neural map of auditory space in the owl. Science 200, 795-797.

Korpilahti, P. H., and Lang, A. (1994). Auditory ERP components and mismatch negativity in dysphasic children. Electroencephalogr. Clin. Neurophysiol. 91, 256-264.

Kraus, N., Koch, D. B., Mcgee, T. J., Nicol, T. G., and Cunningham, J. (1999). Speech-sound discrimination in school-age children: psychophysical and neurophysiologic measures. J. Speech Lang. Hear. Res. 42, 1042-1060.

Kraus, N., McGee, T., Sharma, A., Carrell, T., and Nicol, T. (1992). Mismatch negativity event-related potential elicited by speech stimuli. Ear Hear. 13, 158-164.

Kraus, N., McGee, T., Carrell, T., Sharma, A., Micco, A., and Nicol, T. (1993a). Speech-evoked cortical potentials in children. J. Am. Acad. Audiol. 4, 238-248.

Kraus, N., McGee, T., Micco, A., Sharma, A., Carrell, T., and Nicol, T. (1993b). Mismatch negativity in school-age children to speech stimuli that are just perceptibly different. Electroencephalogr. Clin. Neurophysiol. 88, 123-130.

Kraus, N., McGee, T. J., Carrell, T. D., Zecker, S. G., Nicol, T. G., and Koch, D. B. (1996). Auditory neurophysiologic responses and discrimination deficits in children with learning problems. Science 273, 971-973.

Krumbholz, K., Hewson-Stoate, N., and Schönwiesner, M. (2007). Cortical response to auditory motion suggests an asymmetry in the reliance on inter-hemispheric connections between the left and right auditory cortices. $J$. Neurophysiol. 97, 1649-1655.

Krumbholz, K., Schönwiesner, M., Rübsamen, R., Zilles, K., Fink, G. R., and Von Cramon, D. Y. (2005). Hierarchical processing of sound location and motion in the human brainstem and planum temporale. Eur. J. Neurosci. 21, 230-238.

Kurtzberg, D., Vaughan, H. G. Jr., Kreuzer, J. A., and Fliegler, K. Z. (1995). Developmental studies and clinical application of mismatch negativity: problems and prospects. Ear Hear. 16, 105-117.

Litovsky, R. Y. (1997). Developmental changes in the precedence effect: estimates of minimum audible angle. J. Acoust. Soc. Am. 102, 1739-1745.

Louage, D. H., van der Heijden, M. and Joris, P. X. (2005). Enhanced temporal response properties of anteroventral cochlear nucleus neurons to broadband noise. J. Neurosci. $25,1560-1570$.

Lu, T., Liang, L., and Wang, X. (2001). Temporal and rate representations of time-varying signals in the auditory cortex of awake primates. Nat. Neurosci. 4, 1131-1138.

Maurer, U., Bucher, K., Brem, S., and Brandeis, D. (2003). Development of the automatic mismatch response: from frontal positivity in kindergarten children to the mismatch negativity. Clin. Neurophysiol. 114, 808-817.

May, P. J., and Tiitinen, H. (2010). Mismatch negativity (MMN), the deviance-elicited auditory deflection, explained. Psychophysiology 47, 66-122.

Miller, E. K., and Cohen, J. D. (2001). An integrative theory of prefrontal cortex function. Annu. Rev. Neurosci. 24, 167-202.

Moore, D. R., Cowan, J. A., Riley, A., Edmondson-Jones, A. M., and Ferguson, M. A. (2011). Development of auditory processing in 6- to 11-yr-old children. Ear Hear. 32, 269-285.

Näätänen, R. (1995). The mismatch negativity: a powerful tool for cognitive neuroscience. Ear Hear. 16, 6-18.

Näätänen, R., and Alho, K. (1997). Mismatch negativity-the measure for central sound representation accuracy. Audiol. Neurootol. 2, 341-353.

Näätänen, R., Astikainen, P., Ruusuvirta, T., and Huotilainen, M. (2010). Automatic auditory intelligence: an expression of the sensory-cognitive core of cognitive processes. Brain Res. Rev. 64 123-136.

Näätänen, R., Gaillard, A. W., and Mantysalo, S. (1978). Early selective-attention effect on evoked potential reinterpreted. Acta Psychol. (Amst.) 42, 313-329.

Nääänen, R., and Picton, T. (1987). The N1 wave of the human electric and magnetic response to sound: a review and an analysis of the component structure. Psychophysiology 24, 375-425.

Näätänen, R., Sams, M., Alho, K. Paavilainen, P., Reinikainen, K., and Sokolov, E. N. (1988). Frequency and location specificity of the human vertex N1 wave. Electroencephalogr. Clin. Neurophysiol. 69, 523-531.

Näätänen, R., Simpson, M., and Loveless, N. E. (1982). Stimulus deviance and evoked potentials. Biol. Psychol. 14, 53-98.

Näätänen, R., Tervaniemi, M. Sussman, E., Paavilainen, P., and Winkler, I. (2001). "Primitive intelligence" in the auditory cortex. Trends Neurosci. 24, 283-288.

Nager, W., Kohlmetz, C., Joppich, G. Mobes, J., and Munte, T. F. (2003). Tracking of multiple sound sources defined by interaural time differences: brain potential evidence in humans. Neurosci. Lett. 344 181-184.

Paavilainen, P., Arajarvi, P., and Takegata, R. (2007). Preattentive detection of nonsalient contingencies between auditory features. Neuroreport 18, 159-163.

Paavilainen, P., Jiang, D., Lavikainen, J., and Näätänen, R. (1993). Stimulus duration and the sensory memory trace: an event-related potential study. Biol. Psychol. 35, 139-152.

Paavilainen, P., Karlsson, M. L., Reinikainen, K., and Näätänen, R. (1989). Mismatch negativity to change in spatial location of an auditory stimulus. Electroencephalogr. Clin. Neurophysiol. 73, 129-141.

Pentland, A. (1980). Maximum likelihood estimation: the best PEST. Percept. Psychophys. 28, 377-379.

Pratt, H., Bleich, N., and Mittelman, N. (2005). The composite N1 component to gaps in noise. Clin. Neurophysiol. 116, 2648-2663.

Pratt, H., Starr, A., Michalewski, H. J., Bleich, N., and Mittelman, N. (2008). The auditory $\mathrm{P}(50)$ component to onset and offset of sound. Clin. Neurophysiol. 119, 376-387.

Rauschecker, J. P., and Harris, L. R. (1989). Auditory and visual neurons in the cat's superior colliculus selective for the direction of apparent motion stimuli. Brain Res 490, 56-63.

Sams, M., Paavilainen, P., Alho, K., and Näätänen, R. (1985). Auditory frequency discrimination and event-related potentials. Electroencephalogr. Clin. Neurophysiol. 62, 437-448.

Scherg, M., Vajsar, J., and Picton, T. W. (1989). A source analysis of the late human auditory evoked potentials. J. Cogn. Neurosci. 1, 336-355.

Schröger, E. (1997). On the detection of auditory deviations: a pre-attentive activation model. Psychophysiology 34, 245-257.

Schröger, E. (1998). Measurement and interpretation of the mismatch negativity. Behav. Res. Methods Instrum. Comput. 30, 131-145.

Schröger, E., Näätänen, R., and Paavilainen, P. (1992). Event-related potentials reveal how non-attended complex sound patterns are represented by the human brain. Neurosci. Lett. 146, 183-186.

Shafer, V. L., Morr, M. L., Kreuzer, J. A., and Kurtzberg, D. (2000). Maturation of mismatch negativity in school-age children. Ear Hear. 21, 242-251.

Shestopalova, L. B., and Vaitulevich, S. F. (2005). Effects of the azimuthal position of stationary and moving sound images on the mismatch negativity phenomenon. Neurosci. Behav. Physiol. 35, 855-864.

Siveke, I., Leibold, C., and Grothe B. (2007). Spectral composition of concurrent noise affects neuronal sensitivity to interaural time differences of tones in the dorsal nucleus of the lateral lemniscus. J. Neurophysiol. 98, 2705-2715.

Smith, K. R., Saberi, K., and Hickok, G. (2007). An event-related fMRI study of auditory motion perception: no evidence for a specialized cortical system. Brain Res. 1150, 94-99.

Sonnadara, R. R., Alain, C., and Trainor, L. J. (2006). Effects of spatial separation and stimulus probability on the event-related potentials elicited by occasional changes in sound location. Brain Res. 1071, 175-185.

Sussman, E., Winkler, I., Ritter, W., Alho, K., and Näätänen, R. (1999). Temporal integration of auditory stimulus deviance as reflected by the mismatch negativity. Neurosci. Lett. 264, 161-164

Thompson, N. C., Cranford, J. L., and Hoyer, E. (1999). Brief-tone frequency discrimination by children. J. Speech Lang. Hear. Res. 42, 1061-1068. 
van der Stelt, O., Gunning, W. B., Snel, J., and Kok, A. (1997). No electrocortical evidence of automatic mismatch dysfunction in children of alcoholics. Alcohol. Clin. Exp. Res. 21, 569-575.

van Zuijen, T. L., Simoens, V. L., Paavilainen, P., Näätänen, R., and Tervaniemi, M. (2006). Implicit, intuitive, and explicit knowledge of abstract regularities in a sound sequence: an event-related brain potential study. J. Cogn. Neurosci. 18, 1292-1303.

Wang, W., Datta, H., and Sussman, E. (2005). The development of the length of the temporal window of integration for rapidly presented auditory information as indexed by MMN. Clin. Neurophysiol. 116, 1695-1706.

Warren, J. D., Zielinski, B. A., Green, G. G., Rauschecker, J. P., and Griffiths, T. D. (2002). Perception of soundsource motion by the human brain. Neuron 34, 139-148.

Winkler, I., Tervaniemi, M., Huotilainen, M., Ilmoniemi, R., Ahonen, A., Salonen, O., Standertskjold-Nordenstam, C. G., and Näätänen, R. (1995). From objective to subjective: pitch representation in the human auditory cortex. Neuroreport 6, 2317-2320.

Winkler, I., Tervaniemi, M., Schröger, E., Wolff, C., and Näätänen, R.
(1998). Preattentive processing of auditory spatial information in humans. Neurosci. Lett. 242, 49-52.

Xiang, J., Chuang, S., Wilson, D., Otsubo, H., Pang, E., Holowka, S., Sharma, R., Ochi, A., and Chitoku, S. (2002). Sound motion evoked magnetic fields. Clin. Neurophysiol. 113, 1-9.

Conflict of Interest Statement: The authors declare that the research was conducted in the absence of any commercial or financial relationships that could be construed as a potential conflict of interest.
Received: 21 October 2011; accepted: 12 March 2012; published online: 27 March 2012.

Citation: Ludwig AA, Rübsamen $R$, Dörrscheidt GJ and Kotz SA (2012) Age-related dissociation of sensory and decision-based auditory motion processing. Front. Hum. Neurosci. 6:64. doi: 10.3389/fnhum.2012.00064

Copyright (c) 2012 Ludwig, Rübsamen, Dörrscheidt and Kotz. This is an openaccess article distributed under the terms of the Creative Commons Attribution Non Commercial License, which permits non-commercial use, distribution, and reproduction in other forums, provided the original authors and source are credited. 